\title{
Perceiving text and image in Apollinaire's calligrammes KATHERINE SHINGLER
}

\begin{abstract}
:
Literary scholars have recently become increasingly interested in the perceptual and cognitive mechanisms involved in reading, and have incorporated scientific research in this area into their critical approaches to texts. This article argues that such an approach is particularly appropriate when authors explicitly engage with the way in which their texts are visually taken in and processed. This is the case with Guillaume Apollinaire, whose calligrammes are informed by a theory of visual-verbal simultaneity stipulating that the reader should be simultaneously aware of both textual and pictorial aspects of the poem. Experimental research in the psychology of reading and picture perception is used to assess this theory of simultaneity, and specifically to challenge Michel Foucault's claim that reading and viewing are mutually exclusive processes. The article concludes by considering further applications of psychological research to word and image studies.
\end{abstract}

Keywords: Guillaume Apollinaire, visual poetry, simultaneity, experimental psychology, interdisciplinarity, text and image

Just as the study of visual culture has benefitted from an understanding of the psychology of picture perception, thanks to the pioneering work of scholars such as E. H. Gombrich, Richard Wollheim and John Willats, literary criticism may benefit from an increased understanding of the perceptual and cognitive mechanisms involved in reading. ${ }^{1}$ This has prompted some literary scholars to bring scientific research in this area to bear on their critical approaches, and in some cases to adopt empirical methods to investigate readers' responses to texts. ${ }^{2}$ The need to take 
cognizance of what it is that we do when we read is, however, all the more pressing when authors themselves engage with the way in which their texts are visually taken in and processed by readers. One such author is Guillaume Apollinaire, whose calligrammes, or visual poems, were informed by a theory of visual-verbal simultaneity which insisted on the ability of the readerspectator to deal with visual and verbal aspects of the poem simultaneously. This article aims to investigate readers' perceptual experience of Apollinaire's calligrammes, assessing the theory of simultaneity - which is essentially an empirical claim about the way in which readers are able to attend to and process visual and verbal aspects of poems - in the light of experimental research into the processes underlying reading and picture perception, and the nature of visual attention and awareness.

All poems are visual in the sense that they consist of words laid out on the page, and the reader must look at those words in order to access their meanings. What is special about Apollinaire's calligrammes, along with many other experimentations in typographic form, from Mallarmé's Un Coup de dés through to spatial and concrete poetry, is that the visual aspect of these poems is brought to the forefront of the reader's experience, rendered salient in a way that invites us to view as well as to read them, to attend to their visual as well as their linguistic qualities. Moreover, in his article 'Simultanisme-librettisme', published alongside some of the first calligrammes in the June 1914 issue of the review Les Soirées de Paris, Apollinaire insisted that the processes of reading and viewing should not merely be conjoined, but combined. We are not being asked simply to view poems such as 'La Cravate et la montre' (fig. 1), and then read them, or vice versa, treating reading and viewing as distinct means of apprehending the poem. At the heart of Apollinaire's poetic project is the desire to play down or minimize the distinction between reading and viewing, to bring the two processes into closer contact. As Apollinaire put it, readers should: 
concevoir un poème simultanément comme une scène de la vie, (...) lire d'un seul regard l'ensemble d'un poème, comme un chef d'orchestre lit d'un seul coup les notes superposées dans la partition, comme on voit d'un seul coup les éléments plastiques et imprimés d'une affiche. ${ }^{3}$

(conceive of the poem simultaneously, like a scene from life, (...) read in a single glance the whole of a poem, just as a conductor reads at once the different notes in a score, and as one sees at once both the pictorial and typographic elements of a poster.)

Reading a visual poem is not to be seen as a linear process whereby attention is focused exclusively on one word at a time, in a particular sequence. '[C]oncevoir un poème simultanément comme une scène de la vie' invokes the visual experience of natural scenes as a perceptual model for reading the calligrammes, implying that the reader may be aware of several elements at once, just as in everyday experience we are simultaneously aware of an array of objects occupying different positions within our visual field. Apollinaire further relates the act of reading a calligramme to that of reading a musical score, where it is necessary to attend to multiple elements in parallel. ${ }^{4}$ This analogy implies that the reader should direct attention to several textual or verbal elements at once, but Apollinaire's subsequent reference to poster art makes it clear that the reader's awareness should also span across visual and verbal semiotic systems. In the case of a poster, reading and viewing are not distinct processes, partitioned off from one another: we are, Apollinaire claims, able to take in and interpret 'les éléments plastiques et imprimés' at the same time. Text and image are integrated not just within the space of the poster - or of the printed page - but also within the reader's perceptual experience.

This insistence that reading and viewing should be closely integrated should not be interpreted as an attempt to reduce reading to viewing. More specifically, Apollinaire's claim that we should 'lire d'un seul regard l'ensemble d'un poème' should not be taken literally to imply 
that the whole of the text - all of its verbal elements - may be taken in and processed in a single glance. That this is not a feature of Apollinaire's theory is revealed by a 1913 article, inspired by the Futurist painters' attempts to disrupt Lessing's spatial-temporal dichotomy:

dans la peinture tout se présente à la fois, l'œil peut errer sur le tableau, revenir sur telle couleur, regarder d'abord de bas en haut, ou faire le contraire; dans la littérature, dans la musique, tout se succède et l'on ne peut revenir sur tel mot, sur tel son au hasard. ${ }^{5}$

(in painting, everything is there at once, the eye can wander over the canvas, come back to a given colour, look at the bottom then the top, or vice versa; in literature, in music, there's a succession, and one cannot come back to a given word or sound at will.)

As this passage reveals, Apollinaire is very much aware that when we view pictures and read texts, we are obliged to move our eyes around. The physiology of the retina, where light receptors are concentrated in a central region called the fovea, and become more scarce towards the periphery, means that vision does not provide us with an instantaneous, uniformly detailed 'snapshot' of the whole of the visual field. ${ }^{6}$ We cannot take in the whole of a painting in a single glance, let alone the local details of letter forms: to see anything in detail, we need to direct highresolution foveal vision to it. As such, while 'lire d'un seul regard' certainly hints at the instantaneous visual impact of the printed calligramme, it does not mean that the whole of the text should be read in a single glance (or 'coup d'œil'). Furthermore, Apollinaire recognizes that the patterns of our eye movements differ when we read texts and view images: the reader's inspection of texts will generally follow the particular order of words as they are disposed on the page (albeit with the occasional departure from this linear order), whereas picture perception tends to involve much freer patterns of inspection. ${ }^{7}$ Given this awareness, 'Simultanisme- 
librettisme' cannot be understood as demanding an absolute collapse of the distinction between reading and viewing: Apollinaire understands that the reader will approach a calligramme in two different ways, in order to apprehend and process its visual and verbal aspects. What the theory of visual-verbal simultaneity does demand is that the reader's perceptual experience of the poem should include a simultaneous awareness of textual and visuo-spatial elements, with reading and viewing conceived as two aspects of a single overall interpretative movement, action or process. That is, reading and viewing, while retaining their specificity, should not be partitioned off from one another in our experience: they should be conceived as two sides of the same coin, rather than as two different coins.

This account of the relationship between reading and viewing the calligrammes is brought into question by Michel Foucault in Ceci n'est pas une pipe, which analyses René Magritte's variations on a captioned image of a pipe as 'un calligramme secrètement constitué (...) puis défait avec soin ${ }^{8}$ (a calligramme secretly constructed (...) then carefully undone). Although the calligrammes themselves are not Foucault's main concern, his reading of Magritte is nevertheless reliant on a conception of them as tautological (their visual and verbal meanings coinciding perfectly), and as demanding two distinct and (crucially) mutually exclusive perceptual approaches from the reader. Foucault claims that in order to be able to perceive the shape of the calligramme, to attend to its global features, 'il faut que le regard se tienne au-dessus de tout déchiffrement possible; il faut que les lettres restent points, les phrases lignes, les paragraphes surfaces ou masses' (the gaze must refrain from any decoding; letters must remain dots, sentences lines, paragraphs surfaces or masses). Conversely, reading the text of a calligramme involves attention to the local level of detail at the expense of global spatial layout, so that when we read, our awareness of the poem's shape dissolves:

Dès qu'il se met à lire en effet, la forme se dissipe; tout autour du mot reconnu, de la phrase comprise, les autres graphismes s'envolent, emportant avec eux la 
plénitude visible de la forme, et ne laissant que le déroulement linéaire, successif, du sens.

(As soon as one starts reading, the shape dissolves; around each word one recognizes and each sentence one understands, the other word forms disappear, taking with them the visible plenitude of shape, and leaving behind only the linear, successive unfolding of linguistic sense.)

Foucault concludes from this that,

Par ruse ou impuissance, peu importe, le calligramme ne dit et ne représente jamais au même moment; cette chose qui se voit et se lit est tue dans la vision, masquée dans la lecture. ${ }^{9}$

(Either deliberately or because it is powerless to, it doesn't matter, the calligramme never says and represents at the same time; this thing that is both viewed and read is silenced during viewing, masked during reading.)

Visual-verbal simultaneity fails, according to Foucault, because text and image cannot be apprehended simultaneously. This assessment chimes in with that of other critics, such as Roger Shattuck, who says of Apollinaire's 'Lettre-Océan', 'Our global vision first grasps the Gestalt, the shape of the whole. But this immediate perception has to be completed and corrected by scanning. ${ }^{10}$ Pénélope Sacks-Galey also writes that 'le calligramme n'est qu'exceptionnellement un Gestalt inclusif (comme “1915”, par exemple). Il est impossible d'apprécier simultanément tous ses éléments dans une lecture optique ${ }^{11}$ (the calligramme is only exceptionally an inclusive Gestalt (as with '1915', for example). It is impossible to appreciate simultaneously all of its elements during visual inspection). What these critics are suggesting, in agreement with Foucault, is that viewing the calligramme as a picture involves attention to global features of the poem, 
whereas reading involves attention to a local level of detail. The exception, as Sacks-Galey notes, is a poem like ' 1915 ', where the poem's visual interest is located at the level of letter forms themselves, rather than at the level of global shape, and the reader is therefore unproblematically aware of the poem's special visual qualities as he or she reads. ${ }^{12}$ However, in the case of the majority of Apollinaire's calligrammes (which are usually poems in the shape of objects, like 'La Cravate et la montre'), there is a tension between the global and local levels of information, both competing for our attention. And, according to Foucault, when the reader attends to one of these levels of information, he or she retains no awareness of the other aspect: reading and viewing are mutually exclusive.

Foucault's conception of the calligramme may be clarified through an analogy with ambiguous figures such as Jastrow's duck-rabbit (fig. 2). The spectator sees this either as a duck or as a rabbit at any one time - but never both at once. That is, we experience exclusive, either-or switches from seeing one thing to seeing another thing. Granted, there is a sense in which the content of our visual experience does not change over these switches: the same configuration of lines on the page is present throughout. However, as Wittgenstein's discussion of the duck-rabbit figure suggests, we cannot identify in our own visual experience a 'neutral' stage of vision which precedes the interpretation we clamp upon it; to see something is to see it as something, and in this sense we do see something different when we switch from seeing the figure as a duck to seeing it as a rabbit. ${ }^{13}$ The switches we experience when looking at the ambiguous figure are exclusive because when we see the duck - or attend to the picture's duck-aspect - the rabbitaspect does not enter into our visual awareness at all. Foucault's claim is that the switch from reading to viewing the calligramme is similarly an exclusive, either-or switch in what is seen: the reader is never visually aware of both aspects of the calligramme at the same time.

One source of empirical evidence which might afford a glimpse of how readers actually respond to the calligrammes, and thereby allow us to assess Foucault's and Apollinaire's competing accounts, may be found in eye movement records, which are often used by 
experimental psychologists to investigate the perceptual and cognitive processes involved in visual tasks. With the kind assistance of Paul McGraw, Professor of Visual Neuroscience at the University of Nottingham, I was able to use a high-speed video eye tracker to record the eye movements of a small number of participants (12 in total, a mixture of native and near-native level French speakers, and final-year undergraduates), as they read a selection of calligrammes ('Paysage', 'Loin du pigeonnier' and 'La Cravate et la montre') displayed on a monitor for short durations (40-60 seconds). ${ }^{14}$ The record of the subjects' gaze position during reading was used to generate images such as fig. 3 . The sample was small, and it is difficult to draw any rigorous or statistically sound conclusions, but some very provisional observations may nevertheless be put forward, which I hope will be followed up by future researchers with more refined experimental methods at their disposal. ${ }^{15}$

The major finding was that subjects may adopt a variety of different interpretative strategies in relation to the calligrammes. In particular, different subjects looked at the various elements of the poems in different orders. In the case of 'La Cravate et la montre', most subjects started with the title, moved down to the tie at the top right, and then to the watch; but there was a lot of variation within the figure of the watch. Subjects might choose to read the watch hands and the 'numbers' around its face, as well as the outer contour on the right, in any order - and often moved back and forth repeatedly between these different elements. One subject in fact read the points of the watch face anti-clockwise; the subject reported that she had not identified the shape as a watch and this probably had some impact on her strategy.

The latter subject was in fact one of two who failed to identify some or all of the figures in 'Paysage' and 'La Cravate et la montre', despite the fact that the text (and in the case of the latter poem, the title), contained cues aiding identification. Both subjects reported that they had been too focused on the words making up the poem to give the global shapes any attention, and this was borne out by the eye movement records, which did not contain any evidence of free inspection. One might assume that in natural reading conditions and with no time constraint, these 
subjects would at some point attend to the visual aspect of the poem and identify the figures; but in the experiment, the subjects were exposed to the poems for a maximum of 60 seconds, and this time pressure may have played some role, along with personal preference, in their decision to prioritize the verbal aspect of the poem. Others, however, prioritized the visual aspect of the poem much more; this seemed to be particularly the case with the undergraduates, all of whom had recently studied Apollinaire, and therefore knew that the visual aspect made an important contribution to the poem's overall meaning.

These findings, while provisional, indicate that readers are free to approach Apollinaire's calligrammes in any number of different ways, and although the poems may contain cues prompting the reader to scan its various elements in a certain order (for instance, the inclusion of titles might encourage the reader to start at the top of the page and work downwards), neither order of scanning nor attention to visual and verbal elements can be fully determined by the poem itself. The findings thus support the intuition that a single perceptual model, specifying the experience of a particular calligramme, will be impossible, and that one can only aim to establish some rough parameters regarding what it is possible for readers to do in terms of attending to visual and verbal aspects of these poems. Whilst important in this respect, images of the subjects' scanpaths alone do not allow us to say a great deal about the extent to which visual and verbal aspects are dealt with concurrently, or separately. Although it is possible to identify in these images sequences of fixations which are suggestive of reading (because the eye seems to move from word to word within a sequence), and others which are more suggestive of viewing (because the gaze is not tracking a sequence of words), it may be difficult to identify the precise point at which the subject 'switches' between the two processes. Moreover, some eye movement records are ambiguous, in that it is not immediately obvious whether a sequence of fixations represents either reading or viewing. One subject appeared to be inspecting the global shape of the watch, as she moved quickly from one group of words to another without scanning word-by-word within each group; however, when questioned afterwards, the subject reported that she had in fact been 
fixating isolated words within each group, so as to see whether there was a logical order in which the word groups should be read. This ambiguity makes it difficult to say with any precision whether or not a given subject switched frequently between reading and viewing - so that the two effectively became 'integrated' - or whether they were carried out very much separately. Moreover, even if one could clearly observe in every eye movement record a 'switch' between scanning patterns characteristic of reading, and those characteristic of viewing, the question remains: when the subject is reading, does he or she remain aware of the visual aspect of the poem? And when the subject is viewing the calligramme as an image, does this exclude all awareness of its verbal aspect?

Ultimately, then, these eye movement data beg the very question that we set out to answer: they may tell us where the subject looked and when, but they cannot tell us whether at any given moment the subject was perceptually aware of both word forms and the global shape of the poem. In order to assess Foucault's assertion that visual-verbal simultaneity is impossible, and that reading and viewing are mutually exclusive, we must adopt a different approach. One might begin by questioning the analogy between calligrammes and ambiguous figures implicit in Foucault's account: after all, when we look at a calligramme such as 'La Cravate et la montre' we do not generally see two different images in the global arrangement of marks on the page, as we do with the duck-rabbit. We see one image - which emerges as a global pattern realized by a local level of detail (letters). That is, a calligramme is not an ambiguous figure but a composite figure, other examples of which include Arcimboldo's composite portraits, simple diagrams used by the Gestalt theorists to demonstrate perceptual grouping and the large letters made out of smaller letters widely known as 'Navon figures' through their association with the work of David Navon (fig. 4). Of course, it remains to be proved that the local-textual and global-pictorial levels of structure in the calligramme do not exclude one another in our experience in the way that the image of the duck and the image of the rabbit do. Before presenting evidence relating to this, 
however, some conceptual issues regarding attention and awareness, and the relationship between the two, need to be ironed out.

Attention implies selectivity: 'Attention is the preferential processing of some items to the detriment of others. ${ }^{16}$ Attention is closely related to awareness: in fact, attention may be seen as a selective mechanism for bringing something to the forefront of one's awareness. It follows that if I attend to something within my visual field, I am more aware of it than I am of other things within my visual field. And, if we conceive of attention as a selective bias in one's awareness, then it would seem that attention cannot be split, or directed to more than one thing at once. In this respect, then, we might say that Foucault is correct: we cannot select both the visual and the verbal aspect of the calligramme to come to the forefront of our awareness. It does not follow from this, however, that we retain no awareness whatsoever of the aspect of the poem not attended to. Our attention to one aspect of the poem means that our awareness is biased towards that aspect; and yet that aspect need not be the sole object of our awareness. It may be that our perceptual experience of the calligrammes is 'two-folded', to borrow Richard Wollheim's turn of phrase. Wollheim claims that when we look at representational paintings, two things happen: we are visually aware of the flat, painted surface, and we are aware of depth - of something standing out in front of something else. These two things are not, Wollheim claims, separate experiences, but rather dual aspects of a single experience. I may choose at any time to attend to either aspect of the painting, so that I am more aware of the surface, or more aware of the painting's depth. ${ }^{17}$ But since neither aspect ever completely recedes from my awareness, the switch from attending to one aspect to attending to the other is not exclusive. It is, moreover, not a switch in what is seen, but a more subtle shift in our awareness of different aspects of what is seen. By drawing on research in experimental psychology, I hope to show that what is involved in our experience of composite figures, including the calligramme, is not an exclusive, either-or switch, but a much more subtle shift in our attentional bias towards the global or local features of the poem. 
In a classic study on visual attention, David Navon explored the extent to which we might be simultaneously perceptually aware of both the global and local level of information in composite figures similar to those shown in fig. 4. Navon tested his subjects' perceptual awareness of each level by observing how much it interfered with attention to the other level. In one of his experiments, subjects were presented with Navon figures for short exposures (40 milliseconds), and were asked to name either the small letters or the large letter - to attend to the figures either at the local or the global level. Navon found that where information at the global and local levels conflicted (for example, when a large ' $H$ ' was made out of small ' $F$ 's), this conflict only interfered with the extraction of information at the local level. The subjects were able to exclude the local level from their attention in order to focus solely on the information supplied at the global level. They could not, however, voluntarily ignore the global level: 'whereas people can voluntarily attend to the global pattern without being affected by the local features, they are not able to process the local features without being aware of the whole'. ${ }^{18}$

On the basis of this, attention may be thought of as a kind of filter: it is selective, but not exclusive. We select some information to come through the filter into our awareness, but other information creeps in too - and global information inevitably finds its way in, Navon explaining this by the fact that gaining an initial, global schema of a scene that can subsequently be filled in presents a greater evolutionary advantage than exclusive attention to local detail (p. 355). Navon's study clearly contradicts the part of Foucault's thesis which states that it is impossible to attend to local detail and simultaneously be aware of global structures or patterns, and is lent further support by the work of the experimental psychologist Alan Kennedy on spatial coding in reading. Kennedy's basic claim is that as we read, we build up a mental 'map' of the text in working memory. (Working memory is 'a system that allow[s] several pieces of information to be held in mind at the same time and interrelated', and is used in all everyday cognitive tasks, reading and viewing included). ${ }^{19}$ One source of evidence for spatial coding is the fact that readers are able to make large and very accurate regressive eye movements to regions of previously 
fixated text. In an experiment conducted by Kennedy and Murray, subjects were presented with a sentence, then a target word after the sentence (for example: 'The novels in the library had started to go mouldy with the damp. novels'). The subjects were asked to say whether or not the target word was present in the sentence. Although they probably did not need to, subjects often made a regressive saccade back to the target word in the sentence, and when they did this their gaze typically landed within the boundaries of the target word. Saccadic eye movements are ballistic, meaning that they cannot be redirected once they have been launched; the visual system therefore has to know the location of the word fairly accurately before directing a saccade towards it. Kennedy and Murray also maintain that given the size of the saccades involved (40-50 characters on average in this experiment), it would be extremely difficult, if not impossible, for the subjects to locate the target word using peripheral vision prior to launching the saccade. The spatial coding hypothesis accounts for subjects' ability to make such large and accurate regressive eye movements by positing that they maintain in working memory a record of the spatial location of words fixated on the first pass through a text, enabling refixation if this is needed. ${ }^{20}$

The spatial coding hypothesis is plausible particularly from the point of view of processing efficiency: by treating the page itself as a "spatially-addressed "external memory", the reader reduces the burden on working memory. ${ }^{21}$ Rather than trying to retain in working memory detailed information about the words occurring in a string, and their order, the reader takes advantage of the fact that the text is available as a stable record, and uses a spatial map of the text to guide refixations whenever the 'external memory' provided by the text needs to be consulted. Further studies by Kennedy and his colleagues also indicate that we code the location of words in relation to the most locally available frame of reference, usually the page boundary (rather than in relation to spatial locations in the external world). ${ }^{22}$ This accords with evidence that memory for word locations tends to be page-based, and with a phenomenon that most readers will have experienced: knowing where within the page a given passage is located, but not, unfortunately, on which page. ${ }^{23}$ Kennedy's research is important for our purposes because in highlighting the 
essential role of visuo-spatial cognition in reading, it presents a challenge to what has perhaps been the dominant trend in the psychology of reading from Lessing through to the present day $-\mathrm{a}$ tendency to think of written texts as appealing primarily to the ear rather than to the eye, and of reading as 'surrogate listening, ${ }^{24}$ Countering this view, the spatial coding hypothesis reveals that readers do not focus attention exclusively on one word at a time, or read in a purely linear way opposed to the global awareness required in picture perception; rather, global awareness of the arrangement of text on the page is very much built into the reading process - and this applies even in the case of texts where layout is not a salient feature.

Navon and Kennedy's findings indicate that it would be impossible to direct one's attention exclusively to local word forms and be completely unaware of the calligramme's global shape. ${ }^{25}$ Navon's experiments did nevertheless demonstrate that it is possible for readers to attend to global information without interference from the local level. This does not, however, provide support for the second part of Foucault's argument, which consists in the claim that viewing the calligrammes - attending to their global pictorial structure - excludes awareness of letters and words. Navon's experiment demonstrates only that subjects can devote their attention exclusively to the global levels: they might achieve this by voluntarily degrading the quality of local sensory data - by squinting, for instance, or changing the focus of the eye lens (p. 371). This is perhaps what Foucault means when he talks about seeing the words in the calligramme not as words but as 'points', 'lines', 'surfaces' and 'masses'. One must remember, however, that the experimental task set by Navon involved a time constraint which demanded that attention be devoted exclusively either to global or local information. No such demand is placed on the reader of the calligrammes, who is implicitly asked to be open to interference of the local level on the global, and vice versa. Thus it is the case that while we can ignore local details of word forms, this is by no means the necessary procedure that Foucault claims it to be.

One of the key errors of Foucault's analysis is this assumption that attention to global features of the calligramme involves somehow avoiding any perception of local detail. More 
specifically, Foucault neglects to consider the inhomogeneity of the retina, and the resulting fact that when a picture is viewed, foveal vision will fall on some part of it, providing detailed information about that part. It is impossible, in other words, to hold global vision completely aloof from local details - unless, of course, we squint in order to limit the acuity of those details. Under normal conditions, the process of inspecting the global shape of the calligramme will inevitably involve the direct fixation of some words. Moreover, during viewing, the reader will not only see certain words, making him or her aware of the fact that the global shape is made up of words; he or she will also recognize the fixated words on the basis of their shape, and extract their meanings. This is demonstrated by a phenomenon known as the Stroop effect: when a subject encounters a written word, he or she automatically extracts its meaning, even when this is detrimental to the performance of another task. In one of J. R. Stroop's original experiments, subjects were presented with colour names, each printed in an ink of a different colour to the one named: 'red' written in blue ink, or 'yellow' written in red ink, would be examples of Stroop stimuli. The subjects were asked to identify the colour in which the word was printed. Reaction times for these stimuli, where there was a conflict between the colour name and the colour of the ink, were markedly longer (74\%), compared to the time it took the subjects to name coloured blocks. ${ }^{26}$ In this experiment, subjects were deliberately trying to ignore the word forms, and to attend exclusively to the colour of the ink. Yet the fact that the conflict between the ink colour and the meaning of the words was slowing their performance shows that the word meanings were in fact extracted. This in turn indicates that the direction of attention towards ink colour did not exclude awareness of the word forms, despite the subjects' best efforts. Thus, if a general survey of the shape of a calligramme entails the foveal inspection of some words, the Stroop effect suggests that it will also entail the automatic extraction of their meanings. Of course, this is not quite the same thing as saying that we are able to read and view at the same time, yet it does make it more difficult to set up a hard-and-fast distinction between the two processes, or to claim that exclusive attention to global shape information is possible. 
What we have ended up with is an account of attention and awareness which, ironically, concurs with the thesis of Lessing's Laocoon. Having been subject to various critical hatchet-jobs and deformations, it is often thought that Lessing claims that the union of poetry and painting is impossible - whereas in fact, his claim is that when they are combined, their union will be 'imperfect', and that one will always be subordinated to the other. ${ }^{27}$ This is true from the point of view of the way in which readers apprehend visual poems: attention will always be oriented towards either the visual or verbal aspect at the expense of the other (and, as the eye movement data previously reported indicate, readers are free to prioritize these aspects for attention in any way they choose). And yet, Foucault's conception of the calligramme along the lines of ambiguous figures such as the duck-rabbit has to be rejected in the light of evidence that attention to local-textual and global-spatial aspects of the poem cannot be exclusive. Visual-verbal simultaneity is possible to the extent that readers are capable of integrating awareness of both visual and verbal aspects of the calligramme, and their experience of the poem is in this sense 'twofolded'.

I would like to conclude with some brief considerations on the broad potential, as well as the limits, of the interdisplinary approach adopted here. As well as allowing us to assess the theory of simultaneity underlying Apollinaire's visual poetry, such an approach may yield discoveries about the relationship between reading and viewing that are more widely applicable to other works combining word and image, such as Cubist collage, the livre d'artiste and bande dessinée. For example, the Stroop effect tells us much about the way in which spectators might perceptually deal with verbal elements incorporated into visual works of art. Jasper Johns's painting False Start incorporates Stroop stimuli, and would seem to play directly on the Stroop effect. Indeed, the 'false start' of the title might refer to the interference of the colour name, which is automatically processed, with the viewer's recognition of the coloured patches themselves: the viewer cannot help but experience the painting via its verbal components, even when these conflict with the visual evidence. Equally, the Stroop effect implies that when we 
encounter single words or short phrases within a Cubist collage, we are likely to access their meanings automatically, without consciously stopping 'viewing' and going about 'reading'. More generally, critical discourses on the 'sister arts' of poetry and painting might be further advanced by an increased engagement with the psychology of reading and picture perception; long-running debates surrounding the structural isomorphism of visual and verbal semiotic systems might, for instance, take into account the issue of whether the interpretative processes applied to visual and verbal signs are themselves structurally similar (either at the level of cognitive processes, or at the level of neural events).

We have seen that Apollinaire places the perceptual integration of text and image at the centre of his aesthetic; it is only fitting that his calligrammes should be assessed in the light of the very psychological considerations that informed their composition. Previous critical responses to the question of visual-verbal simultaneity have been based exclusively on introspection, and while first-person accounts of readers' perceptual experience of the calligrammes should certainly not be disregarded, an altogether more nuanced and reliable picture may be obtained by considering the wealth of relevant information available from the field of experimental psychology. The latter must be used, of course, to supplement, rather than to supplant, literary analysis: while it can yield useful information about the reader's perception of visual and verbal elements - and might also shed light on some of the basic interpretative processes involved in reading and viewing - it cannot provide a full account of the way in which meanings are generated, through text or through image, or indeed through a combination of the two. That is a matter for literary criticism. 


\section{NOTES}

I would like to thank Paul McGraw for his help in obtaining eye movement records, and colleagues and students who participated in the eye movement study. I am also grateful to Paul Smith, Richard Hobbs, and many others who have commented on earlier versions of this article.

${ }^{1}$ E. H. Gombrich, Art and Illusion: A Study in the Psychology of Pictorial Representation, 6th edition (London: Phaidon, 2002), Richard Wollheim, Painting as an Art (London: Thames and Hudson, 1987), and John Willats, Art and Representation: New Principles in the Analysis of Pictures (Princeton, NJ: Princeton University Press, 1997).

${ }^{2}$ See, for example, Maria Nella Carminati, Martin H. Fischer, Andrew Roberts and Jane Stabler, 'The Visual Impact of Ottava Rima', The Byron Journal 32:1 (2004), 39-44, and 'Readers' responses to sub-genre and rhyme scheme in poetry', 吕tics, 34 (2006), 204-18; also David Hanauer, 'What we know about reading poetry: theoretical positions and empirical research', in The Psychology and Sociology of Literature, edited by Dick Schram and Gerard Steen (Amsterdam and Philadelphia: John Benjamins, 2001), 107-28.

${ }^{3}$ Guillaume Apollinaire, 'Simultanisme-librettisme', Euvres en prose complètes, edited by Michel Décaudin and Pierre Caizergues, 3 vols (Paris: Gallimard, Bibliothèque de la Pléiade, 1977-93), II, 976. These particular comments were made in relation to Blaise Cendrars and Sonia Delaunay’s ‘livre simultané’ La Prose du Transsibérien et de la petite Jehanne de France (1913), which Apollinaire saw as corresponding directly to his own attempts at a 'simultaneous' visual poetry; see Katherine Shingler, 'Visual-verbal encounters in Cendrars and Delaunay's La Prose du Transsibérien', e-France: An Online Journal of French Studies (forthcoming).

${ }^{4}$ Keith Rayner, 'Eye Movements in Reading and Information Processing: 20 Years of Research', Psychological Bulletin 124:3 (1998), 371-422 (395-6), reports studies showing that skilled music readers do not look directly at each note, but often fixate blank areas, suggesting that they are taking in several surrounding notes at once, while an early study by Miles Tinker ('The Study of 
Eye Movements in Reading', Psychological Bulletin 43:2 (1946), 93-120) indicates that reading music involves vertical as well as horizontal eye movements (104), corresponding to the demand to read several notes or lines of melody in parallel.

${ }^{5}$ Apollinaire, 'A travers le Salon d'Automne', Les Soirées de Paris, November-December 1913, Euvres en prose, II, 620.

${ }^{6}$ Vision research since Helmholtz has been concerned to correct folk-psychological 'passive vision' (or 'snapshot') accounts in light of the fact that vision involves actively seeking out information; see John M. Findlay and Iain D. Gilchrist, Active Vision: The Psychology of Looking and Seeing (Oxford: Oxford University Press, 2003), and Alva Noë, Action in Perception (Cambridge, MA: MIT Press, 2004), 39-55.

${ }^{7}$ On eye movements in reading, see Simon P. Liversedge and John M. Findlay, 'Saccadic eye movements and cognition', Trends in Cognitive Science 4:1 (2000), 6-14 (8-10); around 15\% of the fluent adult reader's eye movements are regressive, moving backwards along the line of text. Alfred L. Yarbus, Eye Movements and Vision, translated by Basil Haigh (New York: Plenum Press, 1968) contains a wealth of eye movement records showing scanpaths used in picture perception.

${ }^{8}$ Michel Foucault, Ceci n'est pas une pipe (Montpellier: Fata Morgana, 1973), 19.

${ }^{9}$ Foucault, Ceci n'est pas une pipe, $26-8$ for all three quotations.

${ }^{10}$ Roger Shattuck, ‘Apollinaire's Great Wheel', in The Innocent Eye: On Modern Literature and the Arts (New York: Farrar Straus Giroux, 1984), 240-62 (260).

${ }^{11}$ Pénélope Sacks-Galey, Calligramme ou écriture figurée. Apollinaire inventeur de formes (Paris: Minard, Lettres Modernes, 1988), 59, n. 2.

${ }^{12}$ Paul Valéry disputed this, arguing that reading for meaning implies more or less bypassing the visual characteristics of words on the page, while attending to their surface features entails that 
we are no longer aware of the meanings of the words; see 'Le Manuscrit' (1926), in Propos sur le livre (Paris: Les Bibliophiles français, 1956), 42.

${ }^{13}$ Ludwig Wittgenstein, Philosophical Investigations, translated by G. E. M. Anscombe (Oxford: Blackwell, 1963), 194-7e.

${ }^{14}$ A Cambridge Research Systems $250 \mathrm{~Hz}$ video eye tracker was used, in conjunction with Video Eyetrace software. The duration of exposure was limited so that the data would be more easily interpretable; longer durations would lead to several passes through the text being superimposed in the eye movement records.

${ }^{15}$ The AHRC-funded project Poetry Beyond Text: Vision, Text and Cognition, led by Andrew Roberts of the University of Dundee and involving researchers from literary and scientific backgrounds, is particularly promising in this respect.

${ }^{16}$ Findlay and Gilchrist, Active Vision, 3.

${ }^{17}$ Richard Wollheim, Painting as an Art, 46-7.

${ }^{18}$ David Navon, 'Forest before Trees: The Precedence of Global Features in Visual Perception', Cognitive Psychology 9 (1977), 353-383 (371).

${ }^{19}$ Alan D. Baddeley, Essentials of Human Memory (Hove: Psychology Press, 1999), 45-6.

${ }^{20}$ Alan Kennedy and Wayne S. Murray, 'Spatial Coordinates and Reading: Comments on Monk (1985)', Quarterly Journal of Experimental Psychology 39 (1987), 649-56.

${ }^{21}$ Alan Kennedy, Rob Brooks, Lesley-Anne Flynn, and Carrie Prophet, ‘The Reader's Spatial Code', in The Mind's Eye: Cognitive and Applied Aspects of Eye Movement Research, edited by Jukka Hyönä, Ralph Radach and Heiner Deubel (Amsterdam: Elsevier Science, 2003), 193-212 (194).

${ }^{22}$ Kennedy et al., 'The Reader's Spatial Code', 200-4.

${ }^{23}$ Ernst Z. Rothkopf, 'Incidental Memory for Location of Information in Text', Journal of Verbal Learning and Verbal Behaviour 10 (1971), 608-13. 
${ }^{24}$ Alan Kennedy, 'Attention Allocation in Reading: Sequential or Parallel?', in Reading as a Perceptual Process, edited by Alan Kennedy, Ralph Radach, Dieter Heller and Joël Pynte (Oxford: Elsevier, 2000), 193-220 (202). On this bias towards the phonological aspect of written language, see also Martin H. Fischer, 'Perceiving Spatial Attributes of Print', in Reading as a Perceptual Process, edited by Alan Kennedy, Ralph Radach, Dieter Heller and Joël Pynte (Oxford: Elsevier, 2000), 89-117 (90), and Alan Kennedy, 'On keeping word order straight. Commentary on E.D. Reichle, K. Rayner and A. Pollatsek, “The E-Z Reader Model of Eye Movement Control in Reading: Comparisons to Other Models", Behavioral and Brain Sciences 26:4 (2003), 490-91.

${ }^{25}$ Of course, this awareness may not be sufficient for identification of the global shape, as the eye movement study reported earlier shows. However, the fact that some subjects did not identify the figures in 'Paysage' and 'La Cravate et la montre' is probably more to do with the complexity and ambiguity of these figures, which are difficult to identify without the cues provided by the text, than with the functioning of visual attention and awareness. Simple, unambiguous figures (such as the larger letters in Navon figures) will most likely always be identified without the need for explicit attention to the global level of structure.

${ }^{26}$ J. Ridley Stroop, 'Studies of Interference in Serial Verbal Reactions', Journal of Experimental Psychology 18:6 (1935), 643-661 (649).

${ }^{27}$ G. E. Lessing, Laocoon, translated by R. Philimore (London: Macmillan and Co., 1874), 3323. 